\title{
Diagnostic or Prognostic Test
}

National Cancer Institute

\section{Source}

National Cancer Institute. Diagnostic or Prognostic Test. NCI Thesaurus. Code C18742.

A test perfomed to identify a disease or make a prediction of the course of the disease. 